\title{
Implementation of intraoperative neurophysiologic monitoring in children and adults in secondary and tertiary health care facilities
}

\author{
Implementación del monitoreo neurofisiológico intraoperatorio en niños y adultos en el \\ segundo y tercer nivel de atención
}
Lilia Cristina De la Maza-Krzeptowsky ${ }^{*}$, Gabriela Romero-Esquiliano², Eduardo H. Ramírez-Segura ${ }^{3}$, Enrique De Obieta-Cruz ${ }^{4}$, Alfonso Vega-Sosa ${ }^{4}$, Alexander Cárdenas-Mejía ${ }^{5}$, Daniel San Juan-Orta ${ }^{6}$, Margot Castillo-Herrera7, Sergio J. Aguilar-Castillo ${ }^{8}$, Mario U. Ávila-Ordóñez, ${ }^{4,9,10,}$ Luz M. Cordero-Guzmán ${ }^{11}$, Rosa E. Escobar-Cedillo7, María I. Fraire-Martínez ${ }^{12}$, Marisela O. Franco-Lira ${ }^{13}$, José J. González-Jaime ${ }^{14}$, Claudia E. Paz-Navarro ${ }^{15}$, Jaime N. Ramos-Peek ${ }^{16}$, Paul Shkurovich-Bialik ${ }^{17}$, Pedro Silva-Cerecedo ${ }^{18}$, C. Armando Tello-Valdés ${ }^{19}$, Álvaro A. Zavala-Reina ${ }^{20,21}$, Jaime López-Rodríguez ${ }^{22}$ and Ojino Sosa-García ${ }^{23}$

${ }^{1}$ Hospital Ángeles del Pedregal, Mexico City; ${ }^{2}$ Universidad Autónoma Metropolitana, Mexico City; ${ }^{3}$ Escuela de Posgrado en Sanidad Naval, Secretaría de Marina-Armada de México, Mexico City; ${ }^{4}$ Hospital General Naval de Alta Especialidad, Secretaría de Marina-Armada de México, Mexico City; ${ }^{5}$ Hospital General Dr. Manuel Gea González, Mexico City; ${ }^{6}$ Instituto Nacional de Neurología y Neurocirugía Manuel Velasco Suárez, Mexico City; ${ }^{7}$ Instituto Nacional de Rehabilitación, Mexico City; ${ }^{8}$ Hospital de Especialidades Centro Médico Nacional Siglo XXI, Instituto Mexicano del Seguro Social (IMSS), Mexico City; ${ }^{9}$ Instituto Nacional de Psiquiatría Dr. Ramón de la Fuente, Mexico City; ${ }^{10} \mathrm{Hospital}$ Psiquiátrico Dr. Samuel Ramírez Moreno, Mexico City; ${ }^{11}$ Instituto Nacional de Pediatría, Mexico City; ${ }^{12}$ Hospital de Pediatría, Centro Médico Nacional Siglo XXI, IMSS, Mexico City; ${ }^{13}$ Secretaría de la Defensa Nacional, Hospital Central Militar, Mexico City; ${ }^{14}$ Antiguo Hospital Civil de Guadalajara Fray Antonio Alcalde, Guadalajara, Jal.; ${ }^{15} \mathrm{Hospital}$ Real San José, Guadalajara, Jal.; ${ }^{16} \mathrm{Hospital}$ Ángeles Mocel, Mexico City; ${ }^{17}$ Centro Médico ABC, Mexico City; ${ }^{18} / \mathrm{MSS}$, Queretaro, Qro.; ${ }^{19} \mathrm{Hospital}$ Español, Mexico City; ${ }^{20} \mathrm{Hospital}$ Médica Sur, Mexico City; ${ }^{21}$ Hospital regional Lic. Adolfo López Mateos, Instituto de Seguridad y Servicios Sociales de los Trabajadores del Estado, Mexico City; ${ }^{22}$ Neurology and Neurological Sciences, and Neurosurgery Stanford University School of Medicine, CA, USA; ${ }^{23}$ Dirección de Integración de Guías de Práctica Clínica, Centro Nacional de Excelencia Tecnológica en Salud, Mexico City, Mexico

\begin{abstract}
Introduction: Intraoperative neurophysiological monitoring (IONM) is a procedure that uses neurophysiological techniques in order to evaluate the motor and sensitive systems during surgeries that endanger the nervous system. Method: The approach, scope, target population, and clinical questions to be answered were defined. A systematic search of the evidence was conducted step by step; during the first stage, clinical practice guidelines were collected, during the second stage systematic reviews were obtained, and during the third stage, clinical trials and observational studies were procured. The MeSH nomenclature and free related terminology were used, with no language restrictions and a 5-10 years frame. The quality of the evidence was graded using the CEPD and SIGN scales. Results: Obtained using the search algorrhythms of 892 documents. Fifty-eight were chosen to be included in the qualitative synthesis. A meta-analysis was not possible due to the heterogeneity of the studies. Conclusions: Eighteen recommendations were issued and will support the adequate use of the IONM.
\end{abstract}

KEY WORDS: Intraoperative neurophysiological monitoring. Clinical practice. Guideline.

\author{
Correspondence: \\ *Lilia Cristina de la Maza Krzeptowsky \\ Camino a Sta. Teresa, 1055 Consultorio 920 Torre \\ Ángeles \\ Col. Héroes de Padierna, Del. Magdalena Contreras \\ C.P. 10700 , Ciudad de México, México \\ Date of reception: $20-10-2017$ \\ E-mail: mtzmaza@yahoo.com.mx \\ Date of acceptance: 09-01-2018 \\ DOI: 10.24875/CIRUE.M18000019
}

Cir Cir. 2018;86:114-121

Contents available at PubMed www.cirugiaycirujanos.com 


\section{Resumen}

Introducción: El monitoreo neurofisiológico intraoperatorio (MNIO) es un procedimiento que emplea técnicas neurofisiológicas con la finalidad de evaluar los sistemas motor y sensitivo durante cirugías que ponen en riesgo al sistema nervioso. Método: Se definieron el enfoque, los alcances, la población diana y las preguntas clínicas por resolver. Se realizó una búsqueda sistematizada de la evidencia por etapas. En la primera, se buscaron guías de práctica clínica; en la segunda, revisiones sistemáticas; y en la tercera, ensayos clínicos y estudios observacionales. Se utilizaron los términos MeSH y libres correspondientes, sin restricciones de lenguaje y con una temporalidad de 5 a 10 años. Se graduó la calidad de la evidencia utilizando las escalas CEPD y SIGN. Resultados: Mediante los algoritmos de búsqueda se obtuvieron 892 documentos, y se seleccionaron 58 para la inclusión de la síntesis cualitativa. Debido a la heterogeneidad entre los estudios, no fue posible realizar metaanálisis. Conclusiones: Se emitieron 18 recomendaciones, las cuales servirán como apoyo para la adecuada utilización del MNIO.

PALABRAS CLAVE: Monitoreo neurofisiológico intraoperatorio. Guía de práctica clínica. Guía.

\section{Introduction}

Intraoperative neurophysiological monitoring (IONM) is a procedure that uses neurophysiological techniques in order to evaluate motor and sensory systems during orthopedic, neurological, vascular and other surgeries that put the nervous system at risk'.

The use of IONM during surgical procedures improves the prognosis of patients undergoing different surgeries. It must be carried out by specialist physicians who are certified by the Councils of Clinical Neurophysiology or Rehabilitation Medicine and who have training in IONM.

IONM is systematically used in different countries of the world ${ }^{2}$. Published studies offer evidence to recommend the use of IONM in various types of surgeries where there is risk of injury to the central or peripheral nervous system ${ }^{3-6}$. IONM has been established to be effective in predicting increased risk for adverse events such as paraparesis, paraplegia and quadriplegia in spinal surgery ${ }^{7}$, showing a sensitivity of $100 \%$ and a specificity of $91 \%$ in the detection of nerve injury ${ }^{4}$. It also can predict facial nerve improvement during facial hemispasm surgery ${ }^{5}$, successfully guide the resection of epileptogenic areas in epilepsy surgery $^{6}$, and alert the surgeon about the possibility of injury to peripheral nerves ${ }^{8}$.

Multimodal IONM implementation reduces the risk of postoperative neurological complications in spinal surgeries by $49.4 \%$, with an average saving of US $\$ 63,387.00$ for neurological deficit prevented per patient ${ }^{9}$.

In Mexico, there is no consensus on the use of IONM in different surgical procedures, and its utilization is low, limited or it is not practiced in public or private tertiary care hospitals. For this reason, the need arises to develop a clinical practice guideline in order to publicize the benefits this procedure provides to the population involved, since with its systematic use in surgeries warranting it, a decrease in the frequency and severity of post-surgical neurological sequelae is expected.

This article presents some recommendations based on the best available evidence, with the purpose to standardize the procedures and to support that IONM decreases the risk of secondary neurological injuries in patients undergoing surgeries involving spinal, cranioencephalic and peripheral nerve structures.

\section{Key recommendations}

- Surgeons and other members of the surgical team should be alerted about the increased risk of neurological adverse effects in patients with transoperative IONM changes.

- Total intravenous anesthesia with propofol is recommended during IONM with somatosensory evoked potentials (SEPS) as the best option for an optimal record of motor and somatosensory potentials.

- The intraoperative cortical mapping technique in children and adults with or without epilepsy using the three-phase tangential or radial multimodal model is safe and reliable for the identification of eloquent areas near the central sulcus (primary somatosensory and motor area).

- Intraoperative electrocorticography (iECoG) is useful in lesional epilepsy surgery (including gangliogliomas) in children and adults to delimit the epileptogenic resection area, guide the resection and evaluate complete resection.

- In carotid endarterectomy surgeries, using electroencephalogram (EEG), transcranial electrical 
stimulation motor evoked potentials (TES-MEPs) and median and tibial nerve SEPs is recommended in order to decide in which patients to perform arterial bridges, initiate intraoperative cerebral neuroprotection measures and reduce the risk of cerebral ischemia.

- IONM of the facial nerve during acoustic neuromas surgery allows preserving the facial nerve function in the immediate postoperative period and at 1-year follow-up.

- IONM of SEPs and cranial nerves from V to XII, excluding VIII, allows reducing neurological deficits during the surgery of small and large tumors of the skull base.

- The use of continuous and evoked electromyography (EMG) is recommended in adult patients for neurological lesions timely detection during root, plexus or peripheral nerve surgeries.

\section{Method}

The group that developed the recommendations was assembled with health professionals specialized in clinical neurophysiology, physical and rehabilitation medicine, neurology, audiology, neurosurgery, plastic and reconstructive surgery, neuroanesthesiology and anesthesiology, who defined the approach, the scope and the clinical questions. The target population were children and adults.

A search for clinical practice guidelines was conducted using the MeSH term "Monitoring, Intraoperative", looking for works published within the last 5 years (from 2009 to date) in English or Spanish. Sixteen results were obtained, out of which one document addressing the clinical practice guidelines in question was used. Subsequently, the search was conducted in PubMed, looking for the types of documents with the largest amount of clinical evidence, after clinical practice guidelines: systematic reviews, meta-analyses and randomized clinical trials; we also searched in websites and databases specialized in the medical area. The reviewed databases were the American University of Beirut Medical Center (one document), PubMed Central (four documents), Springer Link (eight documents), OVIDSP (seven documents), Researchgate (two documents), Science Direct (11 documents) and Wiley Online Library (three documents).

Quality of evidence was graded with the Classification of Evidence for Diagnostic Accuracy (CEPD - Clasificación de la Evidencia para la Precisión Diagnóstica) and Scottish Intercollegiate Guidelines Network (SIGN) systems in order to establish the level of evidence (LoE) and grade of recommendation (GoR). In the case of those questions where no sufficient evidence was found to make a recommendation, a point of good clinical practice was generated, which was also agreed with a $100 \%$ consensus.

The most important key recommendations were selected according to their expected impact. Validation of the content was carried out by a peer clinical expert on the subject who did not participate in the development of the recommendations.

\section{Results}

By means of the search algorithms, 776 documents were obtained, which were verified by title and abstract, with those referring to the "specific" PICO question being reviewed in full text, with 58 documents being selected for inclusion in the qualitative synthesis: one clinical practice guidelines document, two systematic reviews, eight randomized clinical trials, 44 observational studies and one unclassified article.

\section{Recommendations and evidences}

\section{SPINE SURGERY}

Does IONM with SEPS and TES-MEP predict adverse outcomes in spine surgery?

Recommendation: Surgeons and other members of the surgical team should be alerted about the increased risk of adverse neurological effects in patients with transoperative IONM changes (GoR A).

Evidence: In a prospective study ${ }^{6}, 33$ patients who underwent surgical procedures for lesions of the thoracic descending or thoracoabdominal aorta were assessed. SEPs persistent loss was used as a criterion of alarm. No changes were observed in 17 patients. Changes were observed in 16 , and out of these, $5(31 \%)$ had a new neurological deficit. Fisher's exact test: $p=0.0184$.

In a prospective study 7,109 patients on IONM undergoing surgery for spinal tumor resection were assessed: 23 intramedullar, 41 intradural-extramedullar and 45 epidural neoplasms. During the surgical intervention, systemic steroids administration, local hypothermia and other interventions were carried out. A decrease in SEPs amplitude of more than $50 \%$ and an increase of latency greater than $10 \%$ were used as alarm criteria. There was no change in 84 patients, 
whereas 25 did have changes, out of which four (16\%) had a new neurological deficit or worsening of a preexisting one (one paraplegia, one quadriplegia and worsening in two patients with preexisting paraparesis). Fisher's exact test: $p=0.00369$.

Sixty-nine patients were prospectively assessed with SEPs and TES-MEPs in different spinal surgery procedures $^{7}$, using an amplitude decrease $>50 \%$ or a latency increase $>10 \%$ as alarm criteria. Forty-nine patients remained without changes, whereas 20 showed changes, out of which eight $(40 \%)$ had a new neurological deficit.

In a prospective study ${ }^{7}, 52$ patients undergoing spinal surgeries for tumor resection, trauma, spondylolisthesis, scoliosis, vascular malformations and dorsal cysts were assessed. OINM with SEPs was carried out in 38 patients and with TES-MEPs in 12. SEPs and TES-MEPs amplitude decrease $>50 \%$ and $>60 \%$, respectively, were used as alarm criteria. No changes were observed in 45 patients and only five had changes, two of them $(40 \%)$ with neurological deficit (one with paraplegia after surgery and another with paraparesis). Fisher's exact test: $p \leq 0.0158^{7}$ (LoE I).

In patients undergoing spinal surgery with IONM, is there any anesthetic modality that favors the attainment of transoperative neurophysiological responses?

Recommendation: Total intravenous anesthesia with propofol during IONM with SEPs is recommended as the best option for optimal recording of motor and somatosensory potentials (GoR C).

Evidence: In a comparative study of total intravenous anesthesia with propofol versus inhaled anesthesia with isoflurane in 60 patients undergoing spinal surgery with SEPs, SEPs amplitude in the isoflurane group was observed to be significantly $<1.5 \mathrm{mV}$, versus $2.4 \mathrm{mV}$ $(p=0.005)$ in the propofol group ${ }^{10}($ LoE 2+).

\section{INTRACRANIAL SURGERIES}

Does the use of IONM enable the localization of eloquent brain areas in neurosurgical procedures?

Recommendation: The intraoperative cortical mapping technique in adults with nervous system tumors close to the primary somatosensory cortex using the tangential or radial multimodal three-phase model is safe and reliable for identification of eloquent areas close to the central sulcus (primary somatosensory and motor area) (GoR D).

Evidence: In a study of a series of 15 cases (14 adults and 1 boy) with cortical brain tumors, the three-phase radial tangential model associated with electrocorticography and SEPs, applied at a frequency of $50 \mathrm{~Hz}$ and an intensity of 3.7-12 mA (6.2 mA on average), was shown to be a safe intraoperative cortical mapping technique in awake or sedated patients, since lower electrical current intensities are required, which induces fewer seizures (7\%). In addition, it is reliable in the identification of eloquent areas close to the central sulcus (primary somatosensory and motor area), which enables the resection of tumors in these areas, with similar postoperative deficits to those of the other described techniques (13\%). The direct electrical stimulation technique using the low-intensity three-phase tangential model appears to be safe and reduces the risk of intra-operative seizures ${ }^{11}$ (LoE 3).

Is it possible to localize cortical irritative zones with the use of $I E C O G$ in patients undergoing epilepsy surgery?

Recommendation: iECoG in temporal epilepsy surgery is useful to characterize certain electrocorticographic patterns that correlate with focal cortical dysplasia (FCD) histopathological subtypes and allows determining the extent of resection, which may influence on electro-clinical postoperative outcome (GoR D).

Evidence: In a series of 22 epileptic adults, 16 of them with hippocampal sclerosis and type 1 FCD and six only with hippocampal sclerosis, who underwent epilepsy surgery with $\mathrm{EECoG}$ to assess epileptic activity frequency and morphology, a specific electrical pattern was found to be associated with FCD histopathological subtypes (Palmini type 1) in patients with temporal lobe epilepsy and dual pathology ${ }^{12}$ (LoE 3).

Recommendation: iEcoG is useful in lesional epilepsy surgery (including gangliogliomas) in children and adults in order to delimit the epileptogenic resection zone, to guide the resection and to assess complete resection (GoR D).

Evidence: In a series of 157 epileptic children and adults undergoing lesional epilepsy surgery comprehensive perioperative evaluation using IECoG in different brain regions, an improvement in postoperative iECoG was observed in $80 \%$ of patients, which was significantly correlated with clinical improvement, with a sensitivity of $100 \%$, specificity of $68.3 \%$, a positive predictive value of $89.9 \%$ and negative predictive value of $100 \%$ being determined. Seventy-three per cent of patients had a good result according to the Engel scale (I and II), with an average follow-up of $18.2(12-94)$ months $^{13}$ (LoE 2+). 
Recommendation: iECoG-guided resection of cavernomas on different lobes associated with epilepsy in children and adults enables larger resections and predicts an excellent epilepsy control at 2 years (GoR B).

Evidence: One case-control study that included 102 adult patients with an average age of 35.4 years, with cavernomas on different lobes and epilepsy, who underwent iECoG-guided lesionectomy surgery or a more extensive resection, with a follow-up of 37 months, demonstrated an excellent epilepsy control regardless of the cavernoma location, with an Engel class I result in $88 \%$ of patients at 2 years. iECoG enabled more extensive resections. The use of iECoG in cases of temporal lobe cavernomas showed the following distribution of seizure-free results in patients without iECoG vs. iECoG-guided surgery: $79 \%$ (29) vs. $91 \%(23)$ of patients at 6 months post-resection, $77 \%$ (22) vs. $90 \%$ (20) at one year, and $79 \%$ (14) vs. $83 \%$ (18) at 2 years $^{14}($ LoE $2++)$.

Does the use of IONM in carotid endarterectomies help identify patients who require arterial bridging or prevent the loss of cortical functionality during the procedure?

Recommendation: In carotid endarterectomy surgery, using EEG, TES-MEPs and median and tibial nerve SEPs is recommended in order to decide in which patients to perform arterial bridges, to initiate intraoperative cerebral neuroprotection measures and to decrease the risk of cerebral ischemia (GoR B).

Evidence: In a multicenter study at six hospital centers where 668 carotid endarterectomies were performed with EEG and medium and tibial nerve SEPs monitoring, a decrease $\geq 50 \%$ in cortical signal amplitude on EEG or SEPs was found to indicate the need to perform an arterial bridge or initiate cerebral neuroprotection, or both, during surgery. The authors reported that 150 out of 668 surgeries showed a $\geq 50 \%$ amplitude decrease on EEG or SEPs. After surgery, no patient showed data consistent with cerebral ischemia. Neuromonitoring-based selective arterial bridging reduced the risk of cerebral infarction to almost zero when IONM was performed by trained personnel using appropriate protocols ${ }^{15}$ (LoE $2++$ ).

Does facial nerve IONM in patients undergoing cerebellopontine angle surgery help identify and preserve the function in the short and long term?

Recommendation: The monitoring of facial nerve MEPs during facial nerve decompressive surgery predicts immediate and long-term postoperative outcome in adults with hemifacial spasm (GoR D).
Evidence: A case series of 25 adult patients showed that the reduction of facial nerve MEPs amplitude occurred after hemifacial spasm microvascular decompression, with symptoms being resolved in the postoperative period, which suggests a normalization of facial nerve excitability ${ }^{16}$ (LoE 3).

Does the use of IONM in facial nerve extracranial surgeries help identify and preserve its function?

Recommendation: Monitoring of the facial nerve with TES-MEPs enables facial nerve function postoperative preservation in cerebellopontine angle tumors surgeries without the need to directly visualize the facial nerve (GoR C).

Evidence: One prospective study in 68 adult patients with cerebellopontine angle tumors and five with trigeminal neuralgia obtained responses in 57 of 68 patients, with facial nerve TES-MEPs amplitude positively correlating with the degree of tumor extension. Facial nerve TES-MEPs amplitude rates at the beginning and end of surgery were correlated with an early satisfactory result in facial nerve function, which showed the following results: $86 \%$ in House-Brackmann (HB) facial nerve function classification I or II, $67 \%$ in HB III, $33 \%$ in HB IV and $15 \%$ or less in HB V or HB VI ${ }^{18}$ (LoE 2+).

As a complement to intraoperative EMG, TES-MEPs were superior in two aspects: first, in preoperative identification of facial nerve latent lesions, and second, in monitoring the integrity of the nerve without its direct visualization. In all patients whose orbicularis oculis muscles TES-MEPs amplitude rates remained $>50 \%$ had facial nerve satisfactory function (HB I and II) in the immediate and long-term postoperative period (24.4 months) ${ }^{18}$ (LoE 2+).

Recommendation: Facial nerve evoked electromyography ( $\geq 0.05 \mathrm{~mA}$ ) during vestibular schwannoma surgery predicts permanent facial paralysis and improves facial nerve function preservation rates in the postoperative period (GoR B).

Evidence: One study that included 477 adults with vestibular schwannomas showed that facial nerve evoked electromyography $(\geq 0.05 \mathrm{~mA})$ has a specificity of $90 \%$, sensitivity of $29 \%$, a positive predictive value of $68 \%$ and a negative predictive value of $68 \%$ in the detection of permanent facial paralysis. The negative predictive value significantly decreases with the increase in tumor size and in the risk of postoperative facial paralysis ${ }^{19}($ LoE $2++)$.

Recommendation: IONM of the facial nerve during acoustic neuroma surgery allows facial nerve function preservation in the immediate postoperative period and at 1-year follow-up (GoR D). 
Evidence: A retrospective study of 216 patients with acoustic neuromas undergoing surgery with facial nerve IONM showed that facial nerve MEPs amplitude preservation was significantly correlated with facial nerve good function in the immediate postoperative period and at one-year follow-up. To avoid severe facial paralysis, an alarm criterion of an amplitude preservation $>50 \%$ was found to be useful ${ }^{20}$ ( $\operatorname{LoE} 3$ ).

Recommendation: During parotidectomy surgery, facial nerve IONM allows the localization and evaluation of facial nerve continuous function, significantly decreasing temporal paralysis, permanent paralysis and surgical time (GoR A).

Evidence: A systematic review showed that facial nerve MNNO significantly decreases facial nerve temporal and permanent paralysis during parotidectomy surgery. A facial nerve evoked response $\geq 0.5 \mathrm{~mA}$ was predictive of facial nerve postoperative paralysis. Surgical time is reduced with the use of facial nerve IONM $^{21}$ (LoE 1+).

Recommendation: SEPs and cranial nerves V-XII IONM, excluding VIII, allows reducing neurological deficits during the surgery of tumors of the skull base of small and large size (GoR C).

Evidence: The use of cranial nerves $\mathrm{X}, \mathrm{XI}$ and $\mathrm{XII}$ IONM using free EMG and evoked motor responses in 123 adults undergoing skull-base tumor surgeries, helped to reduce the rate of nerve structures injury by surgical manipulation by identifying the course of the cranial nerve in patients with a highly distorted anatomy. These factors can facilitate total macroscopic resection of the tumor with cranial nerve preservation $^{22}$ (LoE 2-).

Does the use of IONM during microvascular decompression of the VIII cranial nerve enable hearing preservation?

Recommendation: The use of monitoring with brainstem auditory evoked potentials (BAEPs) in facial nerve microvascular decompression surgeries is recommended in order to prevent hearing loss; however, no patterns that prevent hearing loss have been established (GoR C).

Evidence: In a retrospective study that included 93 patients who underwent microvascular decompression with cranial nerve VII IONM due to hemifacial spasm, BAEPs were used to assess cranial nerve VII function. The American Academy of Otolaryngology-Head and Neck Surgery hearing loss classification was used to evaluate the results. Hearing changes were observed in $26.88 \%$ of patients, with $17.2 \%$ classified in class $B$ and $9.68 \%$ in class $C / D(\geq 50 \mathrm{~dB}$, hearing not useful). Inter-peak latency changes did not increase the likelihood of hearing loss ${ }^{23}$ (LoE 2+).

\section{SURGERIES INVOLVING THE PERIPHERAL NERVOUS SYSTEM}

In patients undergoing surgeries involving the peripheral nervous system, does IONM using brainstem SEPs reduce neurological lesions associated with the procedure?

Recommendation: The use of brainstem SEPs is recommended in pediatric and adult patients for neurological injury timely detection during root, plexus or peripheral nerve surgery (GoR D).

Evidence: In a case series of 233 pediatric patients undergoing lower limb lengthening and deformity correction surgery, the usefulness of SEPs to detect nerve injury was determined, with a sensitivity of $100 \%$, specificity $91 \%$, a positive predictive value of $100 \%$ and a negative predictive value of $91 \%$ being found ${ }^{4}$ ( $\operatorname{LoE} 3$ ).

In patients undergoing surgeries involving the peripheral nervous system, does IONM with continuous and evoked EMG reduce neurological injuries associated with the procedure?

Recommendation: The use of continuous and evoked EMG is recommended in adult patients for neurological injury timely detection $f$ during root, plexus or peripheral nerve surgery (GoR D).

Evidence: A series of 127 adolescent and adult patients, undergoing hip surgery with continuous EMG recording, showed that $26 \%$ had abnormal neuromyogenic discharges indicative of nervous irritation, which enabled changes in surgical behavior by removing the noxious stimulus. Only $0.7 \%$ had peroneal nerve deficit at more than 1-year follow-up ${ }^{24}$ (LoE 3).

In patients undergoing surgeries involving the peripheral nervous system, does IONM with TES-MEPs reduce neurological injuries associated with the procedure?

Recommendation: The use of TES-MEPs in adult patients is recommended for timely detection of brachial plexus or peripheral nerve injury during shoulder replacement surgery and proximal humerus fracture fixation, with simultaneous recording of multiple muscles being required to achieve higher sensitivity (GoR D).

Evidence: In a series of 30 adult patients undergoing shoulder replacement surgery with TES-MEPs recording in six muscles of the involved limb, 30 alerts were recorded in 17 patients; $97 \%$ of them showed a 
TES-MEPs amplitude decrease $>50 \%$, and in $46.7 \%$ of them there was evidence of injury in several ner$\operatorname{ves}^{25}$ (LoE 3).

In patients undergoing surgeries involving the peripheral nervous system, does IONM with nerve action potentials (NAP) reduce neurological injuries associated with the procedure and help define the surgical procedure?

Recommendation: The use of NAP recording is recommended in plexus and peripheral nerve surgery in order to: 1) identify the nerve; 2) locate preexisting lesions in the nerve; 3 ) determine the functional continuity across the injury; 4) identify root avulsion; 5) identify sites for biopsy taking; 6) prevent damage to the healthy nerve during surgery; and 7) help select the appropriate surgical technique in order to achieve better functional recovery (GoR D).

Evidence: In a retrospective analysis of 1736 patients with 3459 injured nerves, NAPs were recorded through lesions with breaks in continuity in order to identify the damage and define the ideal surgical technique (neurolysis, partial repair, neurorrhaphy or reconstruction with graft). In patients with NAP record and neurolysis, functional recovery equal to or higher than grade 3 according to the Louisiana State University Health Science Center (LSUHSC) scale was $94.7 \%$. In patients with NAP record and neurolysis and mixed repair, functional recovery equal to or higher than grade 3 according to the LSUHSC scale was $94 \%$. In patients without NAP record and reconstruction with graft, recovery equal to or higher than grade 3 according to the LSUHSC scale was $56 \%^{26}$ (LoE 3).

\section{Conclusions}

This article presents some recommendations of the IONM guidelines that were developed by a multidisciplinary group of professionals from different clinical and surgical specialties, which allows approaching the subject from different points of view and enriching the search and final information. With these guidelines, we intend to standardize the criteria on IONM usefulness, systematize its practice and facilitate interdisciplinary communication.

IONM should be used to provide the patient with greater safety in surgical treatment by reducing the risks of postoperative neurological injury, and to provide the physician with real-time information on the functional integrity of the nerve structures involved in the procedure.
We need to continue gathering evidence on OINM usefulness in order to validate its importance in our population, and continuously update it to ensure the validity of recommendations.

\section{Note}

For more information on the clinical practice guidelines Implementación del monitoreo neurofisiológico intraoperatorio en niños $y$ adultos en el segundo $y$ tercer niveles de atención (Implementation of intraoperative neurophysiological monitoring in children and adults at secondary and tertiary care), please visit the CENETEC Clinical Practice Guidelines Master Catalog website (http://www.cenetec-difusion.com/CMGPC/SS-721-14/ER.pdf).

\section{Ethical responsibilities}

Protection of people and animals. The authors declare that no human or animal experiments have been conducted for this investigation.

Confidentiality of data. The authors declare that no patient data appear in this article.

Right to privacy and informed consent. The authors declare that no patient data appear in this article.

\section{Acknowledgements}

We thank the authorities of the institutions the authors belong to.

\section{Conflicts of interest}

The authors declare that there are no conflicts of interest.

\section{Funding}

The authors declare not having received any funding for this work.

\section{References}

1. Skinner SA, Cohen BA, Morledge DE, McAuliffe JJ, Hastings JD, Yingling CD, et al. Practice guidelines for the supervising professional: intraoperative neurophysiological monitoring. J Clin Monit Comput. 2014;28:103-111.

2. Malhotra NR, Shaffrey $\mathrm{Cl}$. Intraoperative electrophysiological monitoring in spine surgery. Spine (Phila Pa 1976). 2010;35:2167-79.

3. Ney JP, van der Goes DN. Evidence-based guideline update: intraoperative spinal monitoring with somatosensory and transcranial electrical motor evoked potentials. Report of the Therapeutics and Technology Assessment Subcommittee of the American Academy of Neurology and the American Clinical Neurophysiology Society. Neurology. 2012;79:292. 


\section{L.C. Maza-Krzeptowsky, et al.: Implementation of intraoperative neurophysiologic}

4. Makarov MR, Samchukov ML, Birch JG, Cherkashin AM, Sparagana SP Delgado MR. Somatosensory evoked potential monitoring of periphera nerves during external fixation for limb lengthening and correction of deformity in children. J Bone Joint Surg Br. 2012;94:1421-6.

5. Sekula RF Jr, Bhatia S, Frederickson AM, Jannetta PJ, Quigley MR, Small GA, et al. Utility of intraoperative electromyography in microvascular decompression for hemifacial spasm: a meta-analysis. Neurosurg Focus. 2009;27:E10.

6. Simon MV, Cole AJ, Chang EC, Buchbinder BR, Stufflebeam SM Nozari A, et al. An intraoperative multimodal neurophysiologic approach to successful resection of precentral gyrus epileptogenic lesions. Epilepsia. 2012:53:75-9.

7. Nuwer MR, Emerson RG, Galloway G, Legatt AD, Lopez J, Minahan R, et al.; American Association of Neuromuscular and Electrodiagnostic Medicine. Evidence-based guideline update: intraoperative spinal monitoring with somatosensory and transcranial electrical motor evoked potentials. J Clin Neurophysiol. 2012;29:101-8.

8. Sutter M, Hersche O, Leunig M, Guggi T, Dvorak J, Eggspuehler A. Use of multimodal intra-operative monitoring in averting nerve injury during complex hip surgery. J Bone Joint Surg Br. 2012;94:179-84.

9. Ney JP, van der Goes DN, Watanabe JH. Cost-effectiveness of intraoperative neurophysiological monitoring for spinal surgeries: beginning steps. Clin Neurophysiol. 2012;123:1705-7.

10. Liu EH, Wong HK, Chia CP, Lim HJ, Chen ZY, Lee TL. Effects of isoflurane and propofol on cortical somatosensory evoked potentials during comparable depth of anaesthesia as guided by bispectral index. $\mathrm{Br} \mathrm{J}$ Anaesth. 2005;94:193-7.

11. Korvenoja A, Kirveskari E, Aronen HJ, Avikainen S, Brander A, Huttunen J, et al. Sensorimotor cortex localization: comparison of magnetoencephalography, functional MR imaging, and intraoperative cortical mapping. Radiology. 2006;241:213-22

12. Morales Chacón L, Estupiñán B, Lorigados Pedre L, Trápaga Quincoses O, García Maeso I, Sánchez A, et al. Microscopic mild focal cortical dysplasia in temporal lobe dual pathology: an electrocorticography study. Seizure. 2009;18:593-600.

13. Tripathi M, Garg A, Gaikwad S, Bal CS, Chitra S, Prasad K et al. Intra-operative electrocorticography in lesional epilepsy. Epilepsy Res. 2010;89:133-41.

14. Van Gompel JJ, Rubio J, Cascino GD, Worrell GA, Meyer FB. Electrocorticography-guided resection of temporal cavernoma: is electrocortico- graphy warranted and does it alter the surgical approach? J Neurosurg. 2009;110:1179-85.

15. Liu H, Di Giorgio AM, Williams ES, Evans W, Russell MJ. Protocol for electrophysiological monitoring of carotid endarterectomies. J Biomed Res. 2010;24:460-6.

16. Fukuda M, Oishi M, Hiraishi T, Fujii Y. Facial nerve motor-evoked potential monitoring during microvascular decompression for hemifacial spasm. J Neurol Neurosurg Psychiatry. 2010;81:519-23.

17. Matthies C, Raslan F, Schweitzer T, Hagen R, Roosen K, Reiners K Facial motor evoked potentials in cerebellopontine angle surgery: technique, pitfalls and predictive value. Clin Neurol Neurosurg. 2011;113:872-9.

18. Fukuda M, Oishi M, Hiraishi T, Saito A, Fujii Y. Intraoperative facial nerve motor evoked potential monitoring during skull base surgery predicts long-term facial nerve function outcomes. Neurol Res. 2011;33:578-82.

19. Sughrue ME, Kaur R, Kane AJ, Rutkowski MJ, Kaur G, Yang I, et al. The value of intraoperative facial nerve electromyography in predicting facial nerve function after vestibular schwannoma surgery. J Clin Neurosci. 2010;17:849-52.

20. Amano M, Kohno M, Nagata O, Taniguchi M, Sora S, Sato H. Intraoperative continuous monitoring of evoked facial nerve electromyograms in acoustic neuroma surgery. Acta Neurochir (Wien). 2011;153:1059-67.

21. Eisele DW, Wang SJ, Orloff LA. Electrophysiologic facial nerve monitoring during parotidectomy. Head Neck. 2010;32:399-405.

22. Topsakal C, Al-Mefty O, Bulsara KR, Williford VS. Intraoperative monitoring of lower cranial nerves in skull base surgery: technical report and review of 123 monitored cases. Neurosurg Rev. 2008:31:45-53.

23. Thirumala PD, Kassasm AB, Habeych M, Wichman K, Chang YF, Gardner $\mathrm{P}$, et al. Somatosensory evoked potential monitoring during endoscopic endonasal approach to skull base surgery: analysis of observed changes. Neurosurgery. 2011;69(1S):64-76

24. Pring ME, Trousdale RT, Cabanela ME, Harper CM. Intraoperative electromyographic monitoring during periacetabular osteotomy. Clin Orthop Relat Res. 2002;(400):158-64.

25. Nagda SH, Rogers KJ, Sestokas AK, Getz CL, Ramsey ML, Glaser DL, et al. Neer Award 2005: Peripheral nerve function during shoulder arthroplasty using intraoperative nerve monitoring. J Shoulder Elbow Surg. 2007;16(3S):S2-8

26. Robert EG, Happel LT, Kline DG. Intraoperative nerve action potential recordings: technical considerations, problems, and pitfalls. Neurosurgery. 2009;65(4S):A97-104. 